TITLE:

\title{
Boron-ketoiminate-based polymers: fine-tuning of the emission color and expression of strong emission both in the solution and film States.
}

\section{AUTHOR(S):}

Yoshii, Ryousuke; Nagai, Atsushi; Tanaka, Kazuo; Chujo, Yoshiki

\section{CITATION:}

Yoshii, Ryousuke ...[et al]. Boron-ketoiminate-based polymers: fine-tuning of the emission color and expression of strong emission both in the solution and film States.

Macromolecular rapid communications 2014, 35(15): 1315-1319

\section{ISSUE DATE:}

2014-05-21

URL:

http://hdl.handle.net/2433/200236

\section{RIGHT:}

This is the peer reviewed version of the following article:Yoshii, R., Nagai, A. Tanaka, K. and Chujo, Y. (2014), BoronKetoiminate-Based Polymers: Fine-Tuning of the Emission Color and Expression of Strong Emission Both in the Solution and Film States. Macromol. Rapid Commun., 35: 1315-1319, which has been published in final form at http://dx.doi.org/10.1002/marc.201400198. This article may be used for non-commercial purposes in accordance with Wiley Terms and Conditions for Self-Archiving.: This is not the published version. Please cite only the published version.; この論文は出版社版でありません。引用の際には出版社版をご確認ざ利用ください。 
DOI: 10.1002/marc.((insert number)) ((or ppap., mabi., macp., mame., mren., mats.))

\section{Communication} Boron Ketoiminate-Based Polymers: Fine-Tuning of the Emission Color and Expression
of Strong Emission both in the Solution and Film States

Ryousuke Yoshii, Atsushi Nagai, Kazuo Tanaka, and Yoshiki Chujo*

Mr. R. Yoshii, Dr. K. Tanaka, Prof. Y. Chujo

Department of Polymer Chemistry, Graduate School of Engineering, Kyoto University, Katsura, Nishikyo-ku, Kyoto 615-8510, Japan

E-mail: chujo@chujo.synchem.kyoto-u.ac.jp

Dr. A. Nagai

Department of Materials Molecular Science, Institutes for Molecular Science, Higashiyama, Okazaki, Aichi, 444-8787, Japan

In this research, we report the synthesis of boron ketoiminate-containing polymers with large molecular weights $\left(M_{\mathrm{n}}=20,000 \sim\right)$ and their optical properties examined by UV-vis absorption and photoluminescence spectrometries. It was shown that the polymers exhibited strong emission both in the solution and solid states $\left(\Phi_{\mathrm{PL}, \mathrm{THF}}=0.46 \sim 0.80, \Phi_{\mathrm{PL}, \mathrm{film}}=\right.$ 0.13 0.38). These optical properties can be explained by a donor-acceptor interaction between the boron ketoiminate and the electron-donating comonomer such as fluorene or bithiophene. Furthermore, in the solid states, their emission colors can be successfully tuned from blue to orange by the substituents on the nitrogen atom with the difference of the steric hindrance $\left(\lambda_{\mathrm{PL}, \mathrm{THF}}=464 \sim 546 \mathrm{~nm}, \lambda_{\mathrm{PL}, \mathrm{film}}=486 \sim 604 \mathrm{~nm}\right)$.

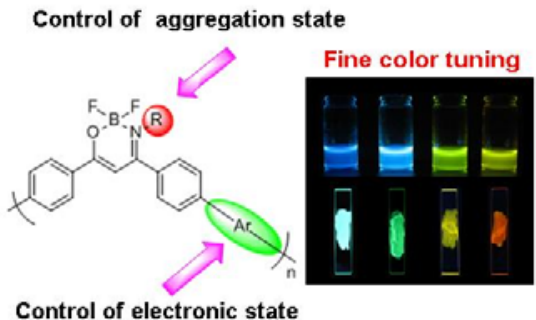




\section{Introduction}

Boron-containing polymers have received a great deal of attention from both academic and industrial researchers. Their superior properties such as high charge-carrier mobilities, prominent optical properties, high stability and high processability make them key materials for the developments of advanced opto and/or electric devices such as organic light emitting diodes, ${ }^{1}$ photovoltaic cells, ${ }^{2}$ and field effect transistors. ${ }^{3}$ We and Jäkle et al. have presented the polymers containing boron complexes in polymer main-chains or side-chains. ${ }^{4,5}$ Accordingly, it was found that these materials showed high stability, high charge-carrier mobilities and strong emission properties as we expected. ${ }^{4,5}$

To apply boron-containing polymers for the light-emitting materials, it is necessary to establish the color-tuning method by simple modifications. Boron diketonate derivatives are known as one of simple and versatile organoboron dyes because of relatively high absorption coefficient, fluorescent quantum yield and high photochemical stability. ${ }^{6}$ Fraser et al. have developed prominent fluorescent and room temperature phosphorescence of boron diketonates 7a,7b and further unique reversible mechanochromic fluorescence of boron avobenzone between solid and melt states. ${ }^{7 c}$ Previously, we have also reported that boron diketonate derivatives and boron diketonates containing polymer showed strong emission in the solution states. ${ }^{8}$ In addition, we have demonstrated that boron ketoiminates which are an analog to boron diketonate showed aggregation-induced emission property. We observed their photoluminescence (PL) properties in the solid states can be easily modulated by the substituents on the nitrogen atom via the change of the molecular stacking structures. ${ }^{9}$ From these results, we presumed that boron ketoiminates could be a promising material as a building block of conjugated polymers with strong emission and fine emission tunability in the solid-state. However, there is room to clarify the fundamental issues such as the degree of the electronic interaction with other functional molecules via the polymer main-chains and the influence of the substituents on the electronic structures. Systematic studies on the electronic 
properties of boron ketoiminate-containing polymers by modulating both of the substituents and the comonomers are required to comprehend the intrinsic properties of boron ketoiminates-containing polymers.

In this research, we report the synthesis of boron ketoiminate-containing polymers and the fine-tuning of their optical properties. The synthesized polymers exhibited strong emission both in the solution and the solid states. Their optical properties were explained by the donoracceptor interaction between the boron ketoiminate as an acceptor unit and the electrondonating comonomer such as fluorene or bithiophene. Furthermore, in the solid states, their emission colors can be tuned from blue to orange by the substituent on the nitrogen atom. This is the first example, to the best of our knowledge, to offer various colorful materials in the wide emission range based on the electronic-structure tuning of the boron ketoiminatecontaining polymers.

\section{Results and Discussion}

As a monomer unit, the diiodo-substituted boron ketoiminates were prepared according to Scheme S1 (see supporting information). Polymerizations were accomplished by the palladium-catalyzed Suzuki-Miyaura coupling with [9,9-bis(2-ethylhexyl)-9H-fluorene-2,7diyl]bisboronic acid (F) or 4,4'-didodecyl-2,2'-bithiophene-5,5'-diboronic acid bis(pinacol) ester (T) in the mixture solvent with toluene and water in the presence of 2dicyclohexylphosphino-2',6'-dimethoxybiphenyl (S-Phos) and $\operatorname{Pd}_{2}\left(\mathrm{dba}_{3}\right.$ (Scheme 1). The terminal units of synthesized polymers were capped with $p$-xylene units. The synthesized polymers showed good solubility in common organic solvents such as THF, $o$-xylene, toluene, chloroform and dichloromethane, etc. The size exclusion chromatography (SEC) in THF with the polystyrene standards revealed the number-average molecular weight $\left(M_{n}\right)$ and the molecular weight distribution $\left(M_{\mathrm{w}} / M_{\mathrm{n}}\right)$ of 24,800 and 2.3 for PF-H, 20,400 and 2.0 for PFMe, 27,500 and 2.6 for PT-H and 32,900 and 2.2 for PT-Me, respectively (Table 1). The 
chemical structures of the polymers were confirmed by ${ }^{1} \mathrm{H},{ }^{13} \mathrm{C}$ and ${ }^{11} \mathrm{~B}$ NMR spectroscopy. All the purified polymers gave satisfactory spectroscopic data corresponding to their expected molecular structures (Figures S1-S6). These observations strongly suggest that the palladiumcatalyzed Suzuki-Miyaura coupling is an effective approach to introduce boron ketoiminates into the main-chain of conjugated polymers.

Initially, the electronic structures at the ground state were examined. The optical properties of the synthesized polymers were investigated by DFT calculations (Figure 1). ${ }^{11} \mathrm{UV}$-vis absorption spectra were obtained in THF $\left(c=1 \times 10^{-5} \mathrm{M}\right.$, Figure 2 and Table 2). In UV-vis absorption spectra, the polymers showed red-shifted absorption bands assigned as $\pi-\pi^{*}$ transitions and smaller HOMO-LUMO gaps (PF-H: $\lambda_{\mathrm{abs}}=409 \mathrm{~nm}, \Delta E=2.79 \mathrm{eV}$, PF-Me: $\lambda_{\mathrm{abs}}=394 \mathrm{~nm}, \Delta E=2.84 \mathrm{eV}$, PT-H: $\lambda_{\mathrm{abs}}=426 \mathrm{~nm}, \Delta E=2.54 \mathrm{eV}$, PT-Me: $\lambda_{\mathrm{abs}}=412 \mathrm{~nm}, \Delta E$ $=2.60 \mathrm{eV})$ comparing to the parent compounds $\left(\mathbf{M}-\mathbf{H}: \lambda_{\mathrm{abs}}=409 \mathrm{~nm}, \Delta E=2.79 \mathrm{eV}, \mathbf{M}-\mathbf{M e}\right.$ : $\left.\lambda_{\mathrm{abs}}=394 \mathrm{~nm}, \Delta E=2.84 \mathrm{eV}\right){ }^{12}$ These results indicate that the $\pi$-conjugated systems were elongated by introduction of the boron ketoiminates into the polymer main-chains. Bithiophene-based polymers (PT-H and PT-Me) showed much red-shifted broad absorptions as compared with fluorene-based polymers (PF-H and PF-Me). The absorption behaviors imply that bithiophene-based polymers could include a strong donor-acceptor interaction between a boron ketoiminate unit and a bithiophene unit having a stronger electron-donating property than that with the fluorene unit. The existence of the donor-acceptor interaction can be supported by the results from density-functional theory (DFT) calculations (Figure 2). The HOMOs of synthesized polymers are localized on a fluorene unit as well as a bithiophene unit, while the LUMOs are localized on a boron ketoiminate unit. In addition, the energy levels of HOMOs are strongly affected by the comonomer units. These data indicate the boron ketoiminate acts as an acceptor in the polymer main-chains. In particular, the localization of HOMOs was clearly presented from the model molecules containing fluorene which can work as a weak electron donor. It is suggested that boron ketoiminate should play a strong electron 
acceptor in the conjugation system. The significant substituent effect by introducing a methyl group at the nitrogen atom was slightly observed according to Figure S8. In summary, it is proposed that the electronic states of the polymers should be strongly affected by the donoracceptor interaction between the boron ketoiminate and the comonomer units.

The PL spectra of the synthesized polymers in THF $\left(c=1 \times 10^{-5} \mathrm{M}\right)$ were measured with the excitation light at each absorption maximum (Figure 3a and Table 2). The polymers showed emissions with a single broad peak. The peak positions of the PL maxima $\left(\lambda_{\mathrm{PL}}\right)$ showed good correlation with the order of their $\Delta E$ values. The bithiophene containing polymers exhibited red-shifted yellow emission comparing to the fluorene containing polymers (PF-H: $\lambda_{\mathrm{PL}}=464$ nm, PF-Me: $\lambda_{\mathrm{PL}}=464 \mathrm{~nm}, \mathbf{P T}-\mathrm{H}: \lambda_{\mathrm{PL}}=546 \mathrm{~nm}$, PT-Me: $\left.\lambda_{\mathrm{PL}}=533 \mathrm{~nm}\right)$. In contrast, the difference of the substituent on the nitrogen atom hardly affected the emission wavelength. This fact corresponds to the results from the DFT calculation.

In the solid states, the emissions of the polymers were obtained in longer wavelength regions than those in THF (Figures 3b). These data can be explained as a strong intermolecular interaction. Especially, PF-H and PT-H showed large shifts. These changes would be originated from smaller steric-hindrance of the hydrogen atom, which induces strong intermolecular interaction in the solid state, in comparison with the methyl group. As a result, in the solid state, the emission color of the polymers can be vividly varied from blue to orange by changing the comonomer and the substituent on the nitrogen atom.

Interestingly, the boron ketoiminate-containing polymers showed strong emission both in solution (in THF, $\left.c=1 \times 10^{-5} \mathrm{M}, \Phi_{\mathrm{PL}, \mathrm{THF}}=0.46 \sim 0.80\right)$ and film states $\left(\Phi_{\mathrm{PL}, \text { film }}=0.13 \sim 0.38\right)$ although the small molecule of the boron ketoiminate derivatives hardly exhibited emissions in the solution states. ${ }^{9,13}$ Therefore, these results suggest that a non-radiative deactivation caused by boron ketoiminate units should be suppressed by introduction of boron ketoiminates into the polymer main-chains. 


\section{Conclusions}

We have demonstrated the effect of a polymerization and a substituent of nitrogen atom on the optical properties of the ketoimine-containing organoboron polymers. It was observed that the polymers exhibited strong emission both in the solution and the film states $\left(\Phi_{\mathrm{PL}, \mathrm{THF}}=\right.$ 0.46 0.80, $\Phi_{\mathrm{PL}, \mathrm{film}}=0.13 \sim 0.38$ ) originated from the introduction of the boron ketoiminates into the polymer main-chains. The optical properties can be explained by a donor-acceptor interaction with the boron ketoiminate as an acceptor. Moreover, the emission colors were significantly varied from blue to orange in the film states by changing the substituents because of the difference of intermolecular interactions in the condensed states. These findings would expand the applicability of boron ketoiminates as a useful building block to prepare a solid-state fluorescent polymer with a fine-tuning ability of optical properties.

\section{Supporting Information}

Supporting Information is available from the Wiley Online Library or from the author.

\section{Acknowledgements}

This work was partially supported by Izumi Science and Technology Foundation (for K.T.), "the Adaptable and Seamless Technology Transfer Program" through target-driven R\&D, Japan Science and Technology Agency (JST) and a Grant-in-Aid for Scientific Research on Innovative Areas "New Polymeric Materials Based on Element-Blocks (No.2401)" (24102013) of The Ministry of Education, Culture, Sports, Science, and Technology, Japan.

Keywords: boron ketoiminate, conjugated polymer, photoluminescence 
[1] a) U. Mitschke, P. Bäuerle, J. Mater. Chem. 2000, 10, 1471. b) D. Li, H. Zhang, Y. Wang, Chem. Soc. Rev. 2013, 42, 8416.

[2] a) C. J. Brabec, N. S. Sariciftci, J. C. Hummelen, Adv. Funct. Mater. 2001, 11, 15. b) R. Stalder, J. Mei, J. Subbiah, C. Grand, L. A. Estrada, F. So, J. R. Reynolds, Macromolecules 2011, 44, 6303. c) R. Casalini, S. W. Tsang, S. J. J. Deininger, F. A. Arroyave, J. R. Reynolds, F. So, J. Phys. Chem. C 2013, 117, 13798.

[3] N. Stutzmann, R. H. Friend, H. Sirringhaus, Science 2003, 299, 1881.

[4] a) Y. Qin, I. Kiburu, S. Shah, F. Jäkle, Macromolecules 2006, 39, 9041. b) F. Cheng, E. M. Bonder, S. Salem, F. Jäkle, Macromolecules 2013, 46, 2905. c) P. Chen, R. A. Lalancette, F. Jäkle, J. Am. Chem. Soc. 2011, 133, 8802. d) F. Jäkle, Chem. Rev. 2010, 110, 3985.

[5] a) K. Tanaka, Y. Chujo, Macromol. Rapid Commun. 2012, 33, 1235. b) K. Tanaka, K. Tamashima, A. Nagai, T. Okawa, Y. Chujo, Macromolecules, 2013, 46, 2969. c) Y. Tokoro, A. Nagai, K. Tanaka, Y. Chujo, Macromol. Rapid Commun. 2012, 33, 550. d) H. Yeo, K. Tanaka, Y. Chujo, Macromolecules, 2013, 46, 2599. e) R. Yoshii, H. Yamane, A. Nagai, K. Tanaka, H. Taka, Y. Chujo, Macromolecules 2014, 47, 2316. f) R. Yoshii, K. Tanaka, Y. Chujo, Macromolecules 2014, 47, 2268. g) Y. Kajiwara, A. Nagai, K. Tanaka, Y. Chujo, J. Mater. Chem. C 2013, 1, 4437. h) K. Tanaka, H. Yamane, R. Yoshii, Y. Chujo, Bioorg. Med. Chem. 2013, 21, 2715. i) R. Yoshii, A. Nagai, K. Tanaka, Y. Chujo, J. Polym. Sci. Part A: Polym. Chem. 2013, 51, 1726.

[6] a) H. Maeda, Y. Mihashi, Y. Haketa, Org. Lett. 2008, 10, 3179. b) K. Ono, K. Yoshikawa, Y. Tsuji, H. Yamaguchi, R. Uozumi, M. Tomura, K. Taga, K. Saito, Tetrahedron 2007, 63, 9354. c) A. G. Mirochnik, E. V. Fedorenko, V. G. Kuryavyi, B. V. Bukvetskii, V. E. Karasev, J. Fluoresc. 2006, 16, 279. d) E. Cogné-Laage, J. -F. Allemand, O. Ruel, J. -B. Baudin, V. Croquette, M. Blanchard-Desce, L. Jullien, Chem. Eur. J. 2004, 10, 1445. e) X. Jiang, X. Liu, Y. Jiang, Y. Quan, Y. Cheng, C. Zhu, Macromol. Chem. Phys. 2014, 215, 358. 
f) F. P. Macedo, C. Gwengo, S. V. Lindeman, M. D. Smith, J. R. Gardinier, Eur. J. Inorg. Chem. 2008, 3200. g) Y. Kubota, S. Tanaka, K. Funabiki, M. Matsui, Org. Lett. 2012, 14, 4682.

[7] a) G. Zhang, J. Chen, S. J. Payne, S. E. Kooi, J. N. Demas, C. L. Fraser, J. Am. Chem. Soc. 2007, 129, 8942. b) G. Zhang, R. E. Evans, K. A. Campbell, C. L. Fraser, Macromolecules 2009, 42, 8627. c) G. Zhang, J. Lu, M. Sabat, C. L. Fraser, J. Am. Chem. Soc. 2010, 132, 2160.

[8] a) A. Nagai, K. Kokado, Y. Nagata, M. Arita, Y. Chujo, J. Org. Chem. 2008, 73, 8605.

b) A. Nagai, K. Kokado, Y. Nagata, Y. Chujo, Macromolecules 2008, 41, 8295.

[9] R. Yoshii, A. Nagai, K. Tanaka, Y. Chujo, Chem. Eur. J. 2013, 19, 4506.

[10] M. J. Frisch, G. W. Trucks, H. B. Schlegel, G. E. Scuseria, M. A. Robb, J. R. Cheeseman, J. A., Jr. Montgomery, T. Vreven, K. N. Kudin, J. C. Burant, J. M. Millam, S. S. Iyengar, J. Tomasi, V. Barone, B. Mennucci, M. Cossi, G. Scalmani, N. Rega, G. A. Petersson, H. Nakatsuji, M. Hada, M. Ehara, K. Toyota, R. Fukuda, J. Hasegawa, M. Ishida, T. Nakajima, Y. Honda, O. Kitao, H. Nakai, M. Klene, X. Li, J. E. Knox, H. P. Hratchian, J. B. Cross, C. Adamo, J. Jaramillo, R. Gomperts, R. E. Stratmann, O. Yazyev, A. J. Austin, R. Cammi, C. Pomelli, J. W. Ochterski, P. Y. Ayala, K. Morokuma, G. A. Voth, P. Salvador, J. J. Dannenberg, V. G. Zakrzewski, S. Dapprich, A. D. Daniels, M. C. Strain, O. Farkas, D. K. Malick, A. D. Rabuck, K. Raghavachari, J. B. Foresman, J. V. Ortiz, Q. Cui, A. G. Baboul, S. Clifford, J. Cioslowski, B. B. Stefanov, G. Liu, A. Liashenko, P. Piskorz, I. Komaromi, R. L. Martin, D. J. Fox, T. Keith, M. A. Al-Laham, C. Y. Peng, A. Nanayakkara, M. Challacombe, P. M. W. Gill, B. Johnson, W. Chen, M. W. Wong, C. Gonzalez, J. A. Pople, Gaussian 03, revision D.01; Gaussian, Inc.: Wallingford CT, 2004.

[11] Results of DFT calculations for PF-Me' and PT-Me' are shown in Figure S8 in Supporting Information. 
[12] The UV-vis absorption spectra of $\mathbf{M - H}$ and M-Me in THF $\left(c=5 \times 10^{-5} \mathbf{M}\right)$ are shown in Figure S7 in Supporting Information. They showed blue-shifted absorption spectra in comparison with the corresponding polymers.

[13] The PL properties of a boron ketoiminate derivative both in the solution and the aggregation state are shown in Figure S9 in Supporting Information. 


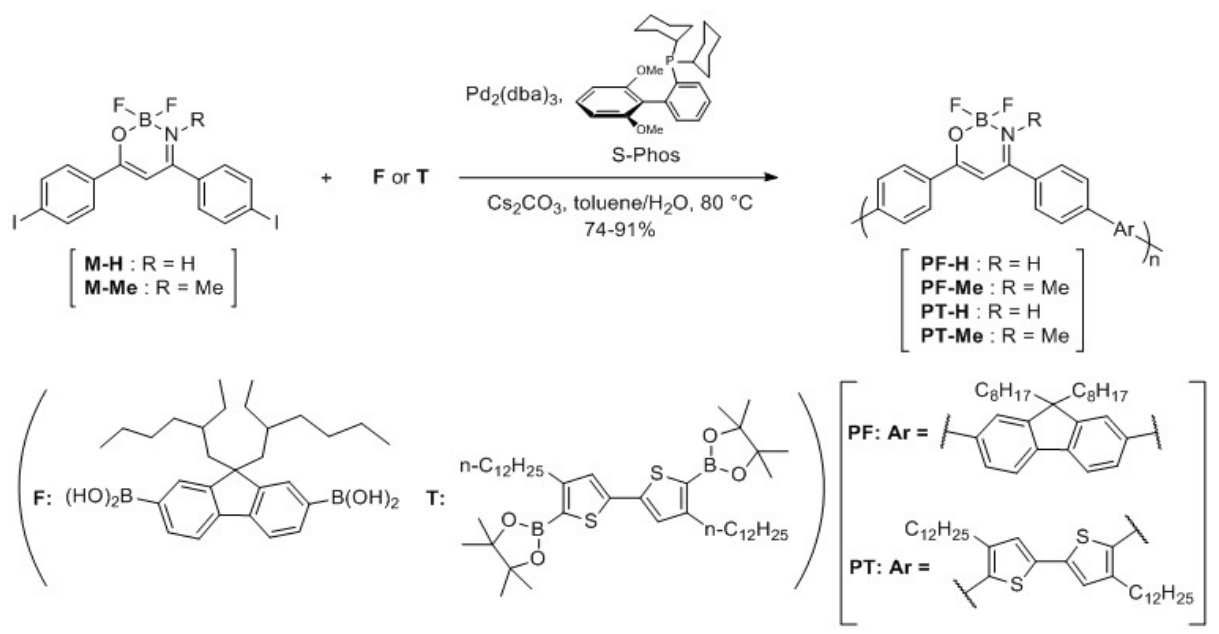

Scheme 1. Synthetic route of the polymers.

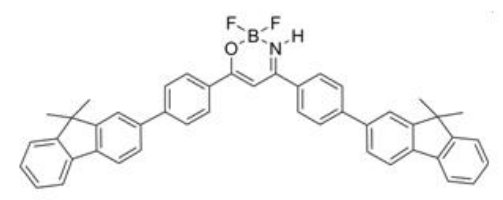

PF-H'

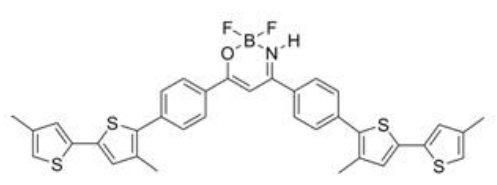

PT-H'

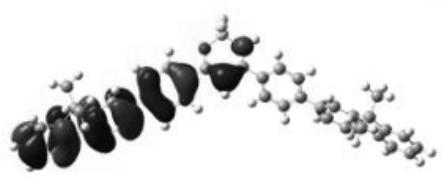

HOMO (-5.67 eV)

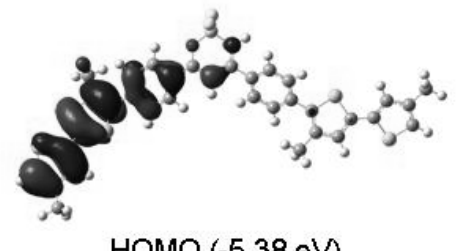

HOMO (-5.38 eV)

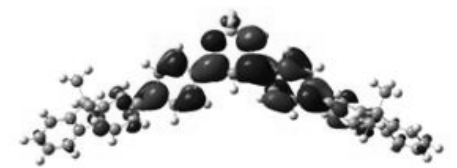

LUMO $(-2.25 \mathrm{eV})$

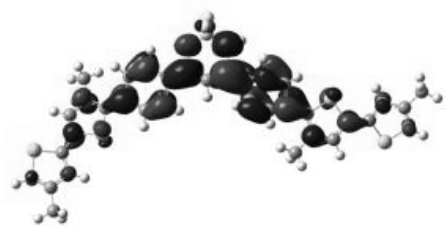

LUMO $(-2.36 \mathrm{eV})$

Figure 1. Structures and molecular orbital diagrams for the LUMO and HOMO of (a) PF-H' and PT-H' ((B3LYP/6-31G (d, p)//B3LYP/6-31G (d, p)). ${ }^{10}$

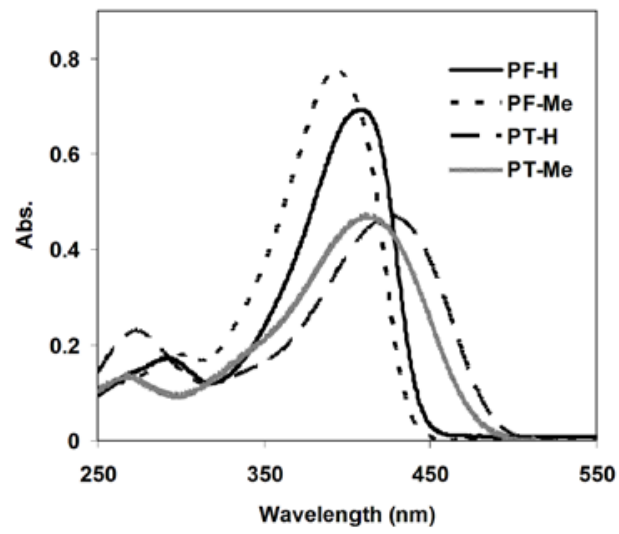

Figure 2. UV-vis absorption spectra of the synthesized polymers in THF $\left(c=1 \times 10^{-5} \mathrm{M}\right)$. 

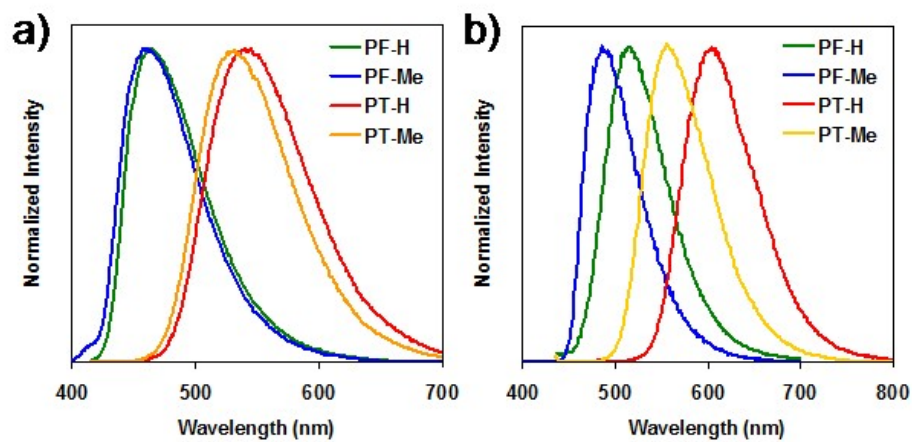

C)

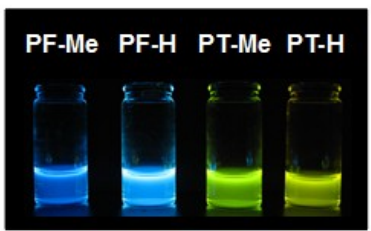

d)

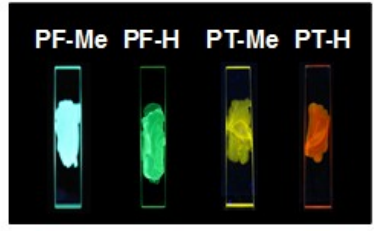

Figure 3. PL spectra of the synthesized polymers in (a) THF $\left(c=1 \times 10^{-5} \mathrm{M}\right)$ and (b) the film state upon the excitation at each absorption maximum. Photographs of the synthesized polymers in (c) THF $\left(c=1 \times 10^{-5} \mathrm{M}\right)$ and (d) the film state under the UV-irradiation.

Table 1. Polymerization results ${ }^{a}$

\begin{tabular}{cccccc}
\hline & $M_{\mathrm{n}}$ & $M_{\mathrm{w}}$ & $M_{\mathrm{w}} / M_{\mathrm{n}}$ & $\mathrm{n}^{b}$ & Yield (\%) $^{c}$ \\
\hline PF-H & 24,800 & 57,000 & 2.3 & 38 & 74 \\
PF-Me & 20,400 & 40,800 & 2.0 & 30 & 91 \\
PT-H & 27,500 & 71,500 & 2.6 & 36 & 82 \\
PT-Me & 32,900 & 72.400 & 2.2 & 42 & 90 \\
\hline
\end{tabular}

a) Estimated by SEC with the polystyrene standards in THF. b) Average number of repeating units calculated from $M_{\mathrm{n}}$ and molecular weights of repeating units. ${ }^{\mathrm{c})}$ Isolated yields after precipitation.

Table 2. Optical properties ${ }^{a, b}$

\begin{tabular}{ccccccc}
\hline & $\lambda_{\mathrm{abs}}{ }^{c}(\mathrm{~nm})$ & $\Delta \mathrm{E}^{d}(\mathrm{eV})$ & $\lambda_{\mathrm{PL}}(\mathrm{nm})$ & $\lambda_{\mathrm{PL}, \text { film }}{ }^{e}(\mathrm{~nm})$ & $\Phi_{\mathrm{PL}}$ & $\Phi_{\mathrm{PL}, \text { film }}{ }^{e}$ \\
\hline PF-H & 409 & 2.79 & 464 & 514 & 0.80 & 0.38 \\
PF-Me & 394 & 2.84 & 464 & 486 & 0.46 & 0.16 \\
PT-H & 426 & 2.54 & 546 & 604 & 0.49 & 0.13 \\
PT-Me & 412 & 2.60 & 533 & 556 & 0.47 & 0.22 \\
\hline
\end{tabular}

a) The PL spectra were measured upon the excitation at each $\lambda_{\text {abs. }}{ }^{\text {b) }}$ The emission quantum yields were determined as an absolute value. ${ }^{\mathrm{c})}$ Measured in THF $\left(c=1.0 \times 10^{-5} \mathrm{~mol} / \mathrm{L}\right)$. $\left.{ }^{\mathrm{d}}\right)$ Calculated from the onset wavelength of the corresponding UV-vis absorption spectra in THF. e) Measured with the cast films from the solutions of synthesized compounds in THF on quartz plates. 
Boron ketoiminate-containing polymers were synthesized by Suzuki-Miyaura coupling, and their optical properties were examined by UV-vis absorption and photoluminescence spectrometries. The polymers exhibited strong emission both in the solution and solid states, and their emission colors were successively tuned from blue to orange by changing the substituents on the nitrogen atom and the comonomer units.

Boron Ketoiminate-Based Polymers: Fine-Tuning of the Emission Color and Expression of Strong Emission both in the Solution and Film States

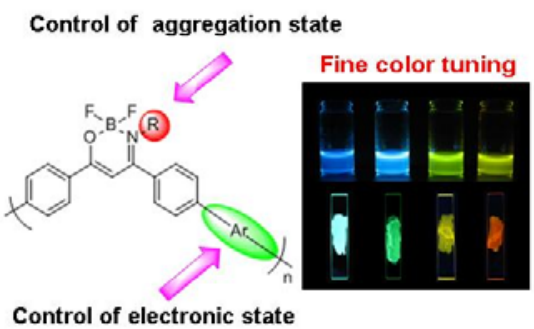

